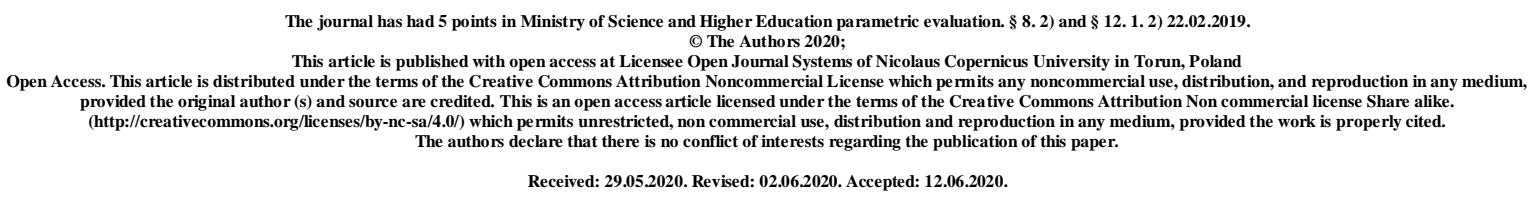

UDK 612.197.23:547.587.11:616.03

\title{
THE ROLE OF POLYUNSATURATED FATTY ACIDS (PUFA) IN THE FORMATION OF THE STRUCTURE AND FUNCTIONS OF BIOMEMBRANES
}

\author{
A. P. Levitsky
}

\section{Odessa National Academy of Food Technologies}

\begin{abstract}
Aim: To show the role of PUFA in the formation of biomembranes and to note the difference between $\omega-6$ and $\omega-3$ PUFA in action on the structure and some membrane functions.

Methods: Analysis of the main publications on this issue over the past 10-15 years.

Results: For the first time, a classification of fatty acids by their origin in the body, from various sources: microbes, plants, animals, is presented. The importance of the intake of long-chain PUFA (C20 and C22), the synthesis of which in the animal organism is limited, is emphasized. The direct effect of PUFA on membrane structures, which is not mediated by the products of their specific oxygenase oxidation, is shown.
\end{abstract}

Key words: polyunsaturated fatty acids; biomembranes; membrane functions.

Fatty acids are organic compounds consisting of a hydrocarbon radical (R) and a carboxyl group $(-\mathrm{COOH})$. The whole variety of fatty acids is determined by the nature of the radical: the length of the hydrocarbon chain (from 2 to 40 carbon atoms), the absence or presence of double bonds in it (from one to six or more), as well as the location of double bonds in the chain. 
Despite the large number of fatty acids (almost 900) [1], there are 4 main groups depending on the source of their origin.

1. Short-chain and medium-chain fatty acids $\left(\mathrm{C}_{2}-\mathrm{C}_{14}\right)$, mainly of microbial origin and some plants may be the source of their origin.

2. Higher fatty acids with a radical length of $\mathrm{C}_{16}-\underline{C}_{18}$, synthesized in humans and animals, as well as in many plants and microorganisms. These include palmitic $\left(\mathrm{C}_{16: 0}\right)$, stearic $\left(\mathrm{C}_{18: 0}\right)$, palmitooleic $\left(\mathrm{C}_{16: 1}\right)$ and oleic $\left(\mathrm{C}_{18: 1}\right)$. These fatty acids are easily synthesized (mainly in the liver) from carbohydrates, amino acids and even alcohol.

3. Polyunsaturated fatty acids with a chain length of 18 carbon atoms and containing

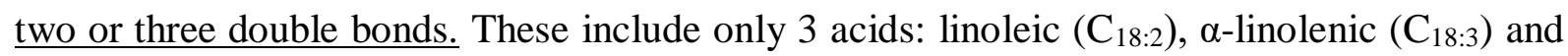
$\gamma$-linolenic $\left(\mathrm{C}_{18: 3}\right)$. The difference between these acids depends not only on the number of double bonds, but also on their location in the hydrocarbon chain with respect to the final methyl group $\left(-\mathrm{CH}_{3}\right)$, denoted by the last letter of the Greek alphabet omega $(\omega)$. If the double bond is located at the third from the end of the carbon atom chain, then such an acid belongs to the $\omega-3$ row, and if at the sixth - then to the $\omega-6$ row.

Linoleic acid, which has two double bonds, one of which is located at the sixth carbon atom is omega-6 PUFA $\left(\mathrm{C}_{18: 2}, \omega-6\right)$. Similarly, $\gamma$-linolenic acid having three double bonds, one of which is located at the sixth carbon atom, belongs to $\omega-6$ PUFA. At the same time, $\alpha-$ linolenic acid, which has three double bonds, but one of which is located at the third from the end of the carbon atom, belongs to the $\omega$-3 PUFA $\left(\mathrm{C}_{18: 3}, \omega-3\right)$.

The main feature of linoleic and linolenic acids is that they do not form in the organism of humans and animals and must necessarily come from food. Therefore, they are called essential or even vitamin $\mathrm{F}$ [2]. The main place for the synthesis of these acids are plants, among which oil plants (sunflower, soybeans, rape, palm trees, flax and others) stand out especially.

4. Polyunsaturated fatty acids with a chain length of 20-22 carbon atoms and containing 4,5 or 6 double bonds. These PUFAs include arachidonic $\left(\mathrm{C}_{20: 4}, \omega-6\right)$, eicosapentaenoic $\left(\mathrm{C}_{20: 5}, \omega-3\right)$, docosapentaenoic $\left(\mathrm{C}_{22: 5}, \omega-6\right)$ and $\left(\mathrm{C}_{22: 5}, \omega-3\right)$, as well as docosahexaenoic $\left(\mathrm{C}_{22: 6}, \omega-3\right)$.

PUFA $\mathrm{C}_{20}-\mathrm{C}_{22}$ can be partially synthesized in the human organism from $\mathrm{C}_{18}-\mathrm{PUFA}$ $[3,4]$, however, the bulk of these acids must come from food (that is, they are also vitamin F) $[2]$. 
The main source of these long-chain PUFA is fish oil and fish from the northern seas (herring, mackerel, sardines, etc.), which accumulate these PUFA, consuming specific algae that carry out their biosynthesis [5-7].

All of the above groups of fatty acids are part of the most important substances of a living organism - lipids, combining both fats (triglycerides) and fat-like substances (phospholipids, sphingomyelins, cholesterol esters and others).

The most important physicochemical property of lipids is their hydrophobicity, which allows them to form structural forms in the aquatic environment, namely biomembranes that create cells and intracellular organelles.

Almost $50 \%$ of the lipids of human erythrocyte membranes are phosphoglycerides (phosphatidylcholine, phosphatidylethanolamine, phosphatidylserine), about 30\% sphingomyelins, and at least 20\% cholesterol esters [8]. At least $35 \%$ of all erythrocyte membrane lipid fatty acids are PUFA, with a ratio of $\omega-6 / \omega-3$ PUFA equal to 2.0 [8].

The content of saturated fatty acids $\left(\mathrm{C}_{16: 0}\right.$ and $\left.\mathrm{C}_{18: 0}\right)$ is $36 \%$ of the total amount of fatty acids of human erythrocyte membrane lipids. The total content of long-chain PUFA $\left(\mathrm{C}_{20}-\mathrm{C}_{22}\right)$ is two times higher than the content of $\mathrm{C}_{18}-\mathrm{PUFA}$ [8].

The table presents the results of determining the content of long-chain PUFA $\left(\mathrm{C}_{20}-\mathrm{C}_{22}\right)$ in membrane phospholipids of mouse organs [9].

Table - Characterization of PUFA of phospholipid membranes of different organs of mice [9]

\begin{tabular}{|l|c|c|}
\hline \multicolumn{1}{|c|}{ Organs } & Content $\mathrm{C}_{20}-\mathrm{C}_{22}$ PUFA & Ratio $\omega-6 / \omega-3$ PUFA \\
\hline Brain & $30,5 \pm 0,3$ & $1,36 \pm 0,20$ \\
\hline Heart & $21,3 \pm 1,8$ & $1,39 \pm 0,20$ \\
\hline Red blood cells & $27,9 \pm 1,7$ & $1,86 \pm 0,20$ \\
\hline Liver & $16,6 \pm 1,5$ & $1,96 \pm 0,10$ \\
\hline Testicles & $21,1 \pm 1,9$ & $0,71 \pm 0,05$ \\
\hline
\end{tabular}

When mice are kept on a high-fat diet, the total amount of $\mathrm{C}_{20}-\mathrm{C}_{22}$ PUFA in mouse tissue phospholipids decreases: in the liver, 2 times, in red blood cells 1.75 times, in the heart 1.44 times, in the brain 1.45 times and testicles 1.53 times [9]. 
It has been established that a decrease in the content of PUFA in membrane lipids or an increase in the ratio of $\omega-6 / \omega-3$ PUFA determine a change in the structural and functional properties of the cell membrane $[10,11]$.

Docosahexaenoic acid $\left(\mathrm{C}_{22: 6}, \omega-3\right)$ accelerates the differentiation and maturation of astrocytes [12].

On isolated sections of the hippocampus of mice, it was shown that eicosapentaenoic acid $\left(\mathrm{C}_{20: 5}, \omega-3\right)$ at a concentration of $20 \mu \mathrm{M}$ reduces the frequency of action potentials of neurons in the CA1 region during electrical stimulation from 3.8 to $2.1 \mathrm{~Hz}$ [13]. These authors have found that eicosapentaenoic acid causes hyperpolarization of the membrane potential of the kidney. Docosahexaenoic acid $\left(\mathrm{C}_{22: 6}, \omega-3\right)$ has a similar effect, in contrast to stearic $\left(\mathrm{C}_{18: 0}\right)$ and oleic $\left(\mathrm{C}_{18: 1}\right)$ acids, which turned out to be inactive. It was found that eicosapentaenoic acid normalizes neuronal excitability, increased glutamate [13]. $\omega-3$ PUFA ( $\mathrm{C}_{20: 5}$ and $\left.\mathrm{C}_{22: 6}\right)$ modified neuronal excitability both in the initial state and in the presence of glutamate.

PUFA with a ratio of $\omega-6 / \omega-3$ equal to 1.1 most actively increase the phagocytic activity of rat macrophages [14]. A similar ratio of PUFA reduced the secretion of proinflammatory cytokines (TNF $\alpha$, IL-6, and IL-8) by human lung carcinoma cells under the influence of lipopolysaccharide, but increased the secretion of the anti-inflammatory cytokine IL-10 [15].

When $14 \mu \mathrm{M}$ arachidonic acid $\left(\mathrm{C}_{20: 4}, \omega-6\right)$ was added to the culture medium with mast cells, the formation of prostaglandin $\mathrm{PGE}_{2}$ and the secretion of histamine and proteases increased [16]. In contrast, the addition of eicosapentaenoic acid $\left(\mathrm{C}_{20: 5}, \omega-3\right)$ had an inhibitory effect on mast cells when stimulated.

Under the action of arachidonic acid $\left(\mathrm{C}_{20: 4}, \omega-6\right)$ on cultured myocytes from rat aortic wall, the expression of monocytic chemoattractate protein-1 and vascular wall adhesin molecules was enhanced [17]. $\omega-3$ PUFA $\left(\mathrm{C}_{20: 5}\right.$ and $\left.\mathrm{C}_{22: 6}\right)$ did not have this effect. Arachidonic acid enhanced the expression of $\mathrm{A}_{2}$ secretory phospholipase under the influence of IL-1 $\beta$, however, $\omega-3$ PUFA blocked this effect.

Arachidonic acid activates the release of calcium ions from the reticulum of skeletal myoblasts [18] and inhibits the development of oxidative stress in various tissues of rats, including the cells of the insular system [19]. Due to this, the introduction of arachidonic acid with food prevents the development of alloxan diabetes.

Antioxidant properties were established not only in arachidonic acid, but also in $\omega-3$ PUFAs ( $\mathrm{C}_{20: 5}$ and $\mathrm{C}_{22: 6}$ ), which were administered to rats with tumors for 42 days at a dose of $120 \mathrm{mg} / \mathrm{kg}$ [20]. At the same time, a decrease in the level of lipid peroxidation in liver 
mitochondria was established, which was evaluated by the content of diene and triene conjugates and MDA.

Practically all PUFA, in addition to structural and direct regulatory functions, have one more, extremely important regulatory function, mediated by physiologically active products of their specific, enzymatic oxidation by enzymes cyclooxygenases and lipoxygenases [2123]. Eicosanoids and docosanoids formed from $\omega-3$ PUFA have anti-inflammatory, immunostimulating and antidysbiotic properties, while eicosanoids formed from $\omega-6$ PUFA, mainly from arachidonic $\left(\mathrm{C}_{20: 4}\right)$, have pro-inflammatory and immunosuppressive properties $[2,6,7,24]$.

In the human organism, both of these systems function in conjunction and perform important protective functions to maintain health.

\section{REFERENCES}

1. Titov VN, Lisitsyn DM. Fat acids. Physical chemistry, biology and medicine. M.-Tver, Triada, 2006: 672. (in Russian)

2. Levitsky AP, Khodakov IV, Lapinskaia AP [and others]. Vitamin F (essential polyunsaturated fatty acids $\omega-6$ and $\omega-3$ PUFA. Odessa, FLP Tashchenko S. Iu., 2020: 65. (in Russian)

3. Wall R, Ross RP, Fitzgerald GF [and others]. Fatty acids from fish: antiinflammatory potential of long-chain omega-3 fatty acids. Nutr. Rev. 2010; 68(5): 280289.

4. Li J, Gu Z, Pan Y [and others]. Dietary supplementation of $\alpha$-linolenic acid induced conversion of n-3 LCPUFAs and reduced prostate cancer growth in a mouse mode. Lipids in Health and Disease. 2017; 16: 136.

5. Gladyshev MI. Essential polyunsaturated fatty acids and their sources for men. Journal of the Siberian Federal University. Biology. 2012; 4(5): 352-386. (in Russian)

6. Belyaeva LE., Pavlyukevich AN. Early programming of human diseases and the use of nutraceuticals for preventive purposes: focus on fish oil. Literature review. Part 1. Bulletin of the Vitebsk State Medical University. 2019; 18(4): 7-16. (in Russian)

7. Belyaeva LE., Pavlyukevich AN. Early programming of human diseases and the use of nutraceuticals for preventive purposes: focus on fish oil. Literature review. Part 2. Bulletin of Vitebsk State Medical University. 2019; 18(5): 12-25. (in Russian) 
8. Novgorodtseva TP, Vedova AV, Zhukova NV. Membrane lipids in patients with chronic bronchitis combined with urolithiasis in the phase of clinical remission. Clinical Laboratory Diagnostics. 2006; 2: 7-9. (in Russian)

9. Valenzuela R, Echeverria F, Ortiz M [and others]. Hydroxytyrosol prevents reduction in liver activity of $\Delta-5$ and $\Delta-6$ desaturases, oxidative stress, and depletion in long chain polyunsaturated fatty acid content in different tissues of high-fat diet fed mice. Lipids in Health and Disease. 2017; 16: 64.

10. Taltavull N, Muñoz-Cortés M, Lluís L [and others]. Eicosapentaenoic acid/docosahexaenoic acid 1:1 ratio improves histological alterations in obese rats with metabolic syndrome. Lipids in Health and Disease. 2014; 13: 31.

11. Calder P. C. Docosahexaenoic acid. Ann. Nutr. Metab. 2016; 69(1): 7-31.

12. Joardar A, Sen AK, Das S. Docosahexaenoic acid facilitates cell maturation and $\beta$ adrenergic transmission in astrocytes. J. Lipid Res. 2006; 47(3): 571-581.

13. Xiaoyong-Fu, Li Xiangyang. Polyunsaturated fatty acids modify mouse hippocampal neuronal excitability during excitotoxic or convulsant stimulation. Brain Research. 1999; 846(1): 112-121.

14. Trushina EN, Mustafina OK, Kulakova SN. Effect of polyunsaturated fatty acids of the diet on the functional activity of phagocytes in rats. Nutrition Issues. 2003; 72(4): 9-11. (in Russian)

15. Cotogni P, Muzio G Trombetta A. [and others]. Inflammatory cytokine release is modified by the ratio of omega- 3 to omega- 6 polyunsaturated fatty acid in human alveolar cells. Nutritional Therapy and Metabolism. 2008; 26(1): 36-44.

16. Gueck T, Seidel A, Fuhrmann H. Consequences of eicosapentaenoic acid (n-3) and arachidonic acid (n-6) supplementation on mast cell mediators. J. Anim. Physiol. and Anim. Nutr. 2004; 88(7-8): 259-265.

17. Bousserouel S, Brouillet A, Béréziat G [and others]. Different effects of n-6 and n3 polyunsaturated fatty acids on the activation of rat smooth muscle cells by interleukin-1 $\beta$. J. Lipid Res. 2003; 44(3): 601-611.

18. Muslikhov ER, Sukhanova IF, Avdonin PV. Arachidonic acid activates the release of calcium ions from the reticulum of skeletal $\mathrm{C} 2 \mathrm{C} 12$ myotubules through ryanosensitive channels. Biochemistry. 2014; 79(5): 553-559. (in Russian)

19. Suresh Y, Das Undurti N. Differential effect of saturated, monounsaturated, and polyunsaturated fatty acids on alloxan-induced diabetes mellitus. Prostaglandins, Leukotrienes and Essential Fatty Acids. 2006; 74(3): 199-213. 
20. Ketsa OV, Marchenko MM. Effect of essential lipophilic nutrients on free radical processes in the mitochondrial fraction of the liver of tumor-carrying rats. Nutrition Issues. 2019; 88(2): 32-39. (in Russian)

21. Folco G, Murphy RC. Eicosanoid transcellular biosynthesis: from cell-cell interactions to in vivo tissue responses. Pharmacol Rev. 2006; 58(3): 375-388.

22. Serhan CN. Pro-resolving lipid mediators are leads for resolution physiology. Nature. 2014; 510(7503): 92-101.

23. Haast RA, Kiliaan AJ. Impact of fatty acids on brain circulation, structure and function. Prostaglandins, Leukotrienes and Essential Fatty Acids. 2015; 92: 3-14.

24. Shikh EV, Makhova AA. Long-chain polyunsaturated fatty acids of the $\omega-3$ family in the prevention of diseases in adults and children: a view of a clinical pharmacologist. Nutrition Issues. 2019; 88(2): 91-100. (in Russian) 